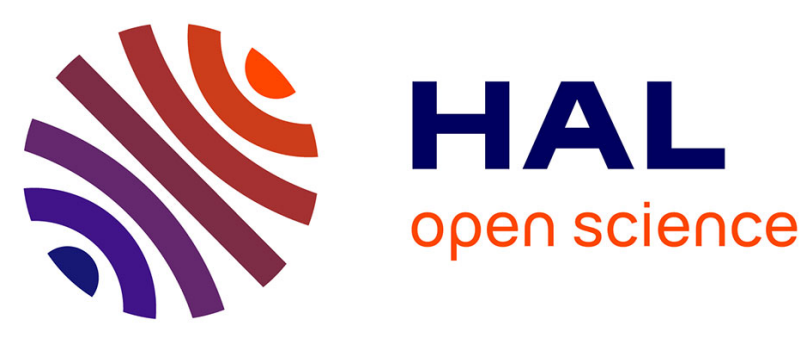

\title{
Autonoetic consciousness in Alzheimer's disease: neuropsychological and PET findings using an episodic learning and recognition task.
}

Géraldine Rauchs, Pascale Piolino, Florence Mézenge, Brigitte Landeau, Catherine Lalevée, Alice Pélerin, Fausto Viader, Vincent de La Sayette, Francis Eustache, Béatrice Desgranges

\section{To cite this version:}

Géraldine Rauchs, Pascale Piolino, Florence Mézenge, Brigitte Landeau, Catherine Lalevée, et al.. Autonoetic consciousness in Alzheimer's disease: neuropsychological and PET findings using an episodic learning and recognition task.. Neurobiol Aging, 2007, 28 (9), pp.1410-20. 10.1016/j.neurobiolaging.2006.06.005 . inserm-00277898

\section{HAL Id: inserm-00277898 https://www.hal.inserm.fr/inserm-00277898}

Submitted on 7 May 2008

HAL is a multi-disciplinary open access archive for the deposit and dissemination of scientific research documents, whether they are published or not. The documents may come from teaching and research institutions in France or abroad, or from public or private research centers.
L'archive ouverte pluridisciplinaire HAL, est destinée au dépôt et à la diffusion de documents scientifiques de niveau recherche, publiés ou non, émanant des établissements d'enseignement et de recherche français ou étrangers, des laboratoires publics ou privés. 
Autonoetic consciousness in Alzheimer's disease:

neuropsychological and PET findings using an episodic learning and recognition task.

Géraldine Rauchs $^{(1)}$, Pascale Piolino ${ }^{(1,2)}$, Florence Mézenge ${ }^{(1)}$, Brigitte Landeau ${ }^{(1)}$, Catherine Lalevée ${ }^{(1,3)}$, Alice Pélerin ${ }^{(1,3)}$, Fausto Viader ${ }^{(1,3)}$, Vincent de la Sayette ${ }^{(1,3)}$, Francis Eustache ${ }^{(1)}$, Béatrice Desgranges ${ }^{(1)}$.

${ }^{(1)}$ Inserm - EPHE - Université de Caen E0218 and GIP Cyceron, France; ${ }^{(2)}$ CNRS, Université René Descartes - Paris 5, France; ${ }^{(3)}$ Service de Neurologie Vastel, CHU Côte de Nacre, Caen, France

\section{Corresponding author:}

Dr Béatrice DESGRANGES

Inserm - EPHE - Université de Caen E0218

Laboratoire de Neuropsychologie, CHU Avenue Côte de Nacre, 14033 CAEN cedex, France.

Phone : +33 (0) 231065196

Fax : +33 (0) 231065198

e-mail : desgranges-b@chu-caen.fr

Keywords: Episodic memory ; Semantic memory ; Frontal lobes ; Parahippocampal gyrus ; Remember/Know paradigm ; cerebral metabolism

Disclosure: The authors have reported no conflicts of interest. 


\section{Abstract:}

Objective: This study aims to map in patients with mild Alzheimer's disease (AD) the correlations between resting-state brain glucose utilization measured by FDG-PET and scores reflecting autonoetic consciousness in an episodic learning and recognition task.

Methods: Autonoetic consciousness, that gives a subject the conscious feeling to mentally travelling back in time to relive an event, was assessed using the Remember/Know $(\mathrm{R} / \mathrm{K})$ paradigm.

Results: AD patients provided less $\mathrm{R}$ responses (reflecting autonoetic consciousness) and more $\mathrm{K}$ ones (indicating the involvement of noetic consciousness) than healthy controls. Correct recognitions associated with a $\mathrm{R}$ response correlated with the metabolism of frontal areas bilaterally whereas those associated with a $\mathrm{K}$ response mainly correlated with the metabolism of left parahippocampal gyrus and lateral temporal cortex.

Conclusions: These data show that recollection is impaired in $\mathrm{AD}$ and recognition is more based on a feeling of familiarity than in controls. In addition, the findings of our correlative approach indicate that the impairment of episodic memory is mainly subserved by the dysfunction of frontal areas and of the hippocampal region. 


\section{Introduction}

Impairment of episodic memory is the earliest and most severe cognitive deficit in Alzheimer's disease (AD) [40,47]. According to the current theoretical frameworks of human memory, episodic memory supports the encoding, storage and retrieval of life's events set in a specific spatio-temporal context. Thus, the term episodic memory encompasses not only autobiographical remote memory but also recently learned information, on which this paper will focus on. Episodic memory is also characterized by autonoetic consciousness, which gives a subject the conscious feeling of travelling backwards in time to relive the original event (for review see [64]). This particular state of consciousness during retrieval of information can be assessed with the Remember - Know $(\mathrm{R} / \mathrm{K})$ paradigm $[23,62]$. Thus, a Remember response means that the subject recollects a specific event as a re-experiencing of the source of acquisition with details (feelings, perceptions, ...). By contrast, a Know response rather corresponds to a feeling of familiarity. "Remembering" is associated with autonoetic consciousness whereas "knowing" is associated with noetic consciousness, which characterizes semantic memory.

The alteration of autonoetic consciousness in $\mathrm{AD}$ has been seldom investigated. Nevertheless, using free and forced-choice recognition tasks, Dalla Barba [9] has shown that "remembering" is more affected than "knowing" in patients with AD. This finding has also been reported using an autobiographical memory task [48]. These results obtained with the Remember/Know paradigm are supported by a series of studies based on other theoretical views but underpinning the idea of a disruption of recollection in AD (see for review [68]). Thus, using an adaptation of the Deese-Roediger-McDermott (DRM) [11,54], a word learning paradigm in which subjects are presented with lists of words in which every item is an associate of a critical non-presented word, Budson et al. [5] showed that AD patients are impaired in their ability to use recollection to reduce, across trials, familiarity-based false 
recognitions. Converging evidence also comes from two studies based on the process dissociation procedure of Jacoby [29]. Thus, both Knight [31] and Koivisto et al. [33], using a word-stem completion task in which subjects had to produce the first word that came to mind in response to each stem without using previously studied words, found that AD patients were less likely than control subjects to use recollection to inhibit erroneous responses. In addition, in an investigation of associative recognition in mild AD patients, Gallo et al. [22] presented participants with unrelated word pairs once or three times and found that false alarms to rearranged pairs following repetition increased in $\mathrm{AD}$ patients but not in elderly controls. Their results suggest that, contrary to controls, AD patients could not use a recollection-based strategy ("recall-to-reject strategy") to counter the increased familiarity of rearranged pairs and confirm that recollection-based monitoring processes are early impaired in AD. All these studies, carried out with various paradigms, acknowledge that recollection is impaired in AD. However, to the best of our knowledge, none of them has investigated the neural bases of this impairment.

Voxel-based mapping of the correlations between memory performance and resting-state cerebral metabolic rates of glucose (CMRGlc) measured by positron emission tomography (PET) is a sensitive approach to delineate the neural substrates of cognitive impairment in AD [e.g., 13,14,28,45,46,57]. Thus, it has been shown that episodic memory impairments observed in $\mathrm{AD}$ are subserved by the dysfunction of not only the hippocampal region but also by the dysfunction of an extensive neural network including the posterior cingulate gyrus ([13], see also [44] for similar conclusions obtained with a different method) and the temporoparietal and frontal association cortices [13]. This methodological approach has been successfully used to unravel the neural substrates of various deficits of episodic memory such as free [19] and cued recall [34], recognition [35], but also for more subtle deficits such as production of intrusions [15] and autobiographical memory impairment for different life-time 
periods [20]. Nevertheless, it has never been used so far to investigate, in $\mathrm{AD}$, the impairment of autonoetic consciousness, a prominent feature of episodic memory.

The aim of this study was therefore to unravel the neural substrates of episodic memory and autonoetic consciousness impairment in mild AD. In this purpose, we used PET and statistical parametric mapping (SPM) to map the correlations between CMRGlc and measures of episodic memory and autonoetic consciousness, assessed by means of an episodic learning and recognition task (adapted from the Grober and Buschke's procedure [25]) associated with the $\mathrm{R} / \mathrm{K}$ paradigm [23].

\section{Methods}

\subsection{Subjects}

Thirteen unmedicated patients (7 women, 6 men; mean age \pm SD: $76.7 \pm 3.8$ years) with a MMSE score [21] of 21 or higher (mean MMSE score \pm SD: $24.8 \pm 2.4$, range 21-28) participated in this study. They were all recruited through a memory clinic, and all complained of memory impairment. All were selected prospectively on the basis of a neurological examination and a neuropsychological assessment, using the National Institute of Neurological and Communicative Disorders and Stroke and the Alzheimer's Disease and Related Disorders Association criteria for probable AD [38]. Structural imaging (MRI) showed no focal abnormality. At the time of the study, none of the patients was being or had been treated with specific medication, such as anti-acetylcholinesterase agents.

Neuropsychological data of AD patients were compared to those obtained in a group of ten healthy elderly subjects (6 women, 4 men; mean age \pm SD: $76.7 \pm 4.1$ years) recruited in clubs for retired people. They had no neurological or psychiatric disorders. The mean score $( \pm$ SD) for the MMSE was $29.4( \pm 1)$. These subjects were paired according to their level of education with $\mathrm{AD}$ patients. 
All subjects were right-handed, native French speakers and gave their written consent to the study after detailed information was provided to them. The study was done in-line with the Declaration of Helsinki following approval by the Regional Ethics Committee.

\subsection{Behavioral paradigm}

Episodic memory was assessed using an original task derived from Grober and Buschke's procedure [25] that consisted in learning a series of 15 words in five successive trials. This procedure was designed to limit the interference from semantic memory impairment by using only items whose semantic integrity has been strictly verified individually. To this end, the semantic integrity of the words to learn was controlled for each patient before the learning phase with questions exploring both general and specific knowledge of each item (see [24] for a detailed description of this task). Once this procedure finished, the episodic memory task was proposed after a 4- to 6-hour delay. This task consists in learning 15 words, presented by series of three on separate cards. The subject is asked to point out and to read aloud each item (e.g., salad) in response to the name of its category, verbally given by the examiner as a cue (e.g., vegetable). Once all three words have been correctly named, the three cards are removed and an immediate verbal cued recall is proposed, in the same order as in the previous identification task, again in response to the category cue (e.g., what was the vegetable?). If the subject is unable to recall an item in response to its cue, the pointing and reading aloud procedure is repeated for this item until a correct response is obtained. Once the immediate cued recall for a group of three items has been correctly performed, the next set of items is presented. Immediately following the processing of the 15 items, retrieval is assessed with cued recall using the same cues as in the learning phase. The originality of this task lies in the fact that we proposed five consecutive trials of cued recall to favour the encoding of most of the words and to avoid, as much as possible, floor effects when retesting AD patients the day 
after. A delayed cued recall and a yes/no recognition task (with 15 semantic and 15 neutral distractors) were proposed after a night of sleep (i.e., a 12-h delay between learning and recall).

The recognition task was associated with the Remember - Know paradigm [23,62] which requires subjects to give either a "Remember" (R) response if retrieval is accompanied by the recollection of specific experiences present at encoding, or a "Know" $(\mathrm{K})$ response if retrieval is achieved on the basis of a feeling of familiarity. These judgment categories were explained very carefully to the patients until each concept was thoroughly understood. Thus, for each word recognized, subjects had to indicate if they specifically remembered it from the list ( $\mathrm{R}$ response) or if they merely knew that the word belonged to the list (K response). For example, remembering a word had to be associated with the re-experience of a particular association, or personal feeling (e.g., for the word 'Snail': "I remember seeing it, making an image of it" or "It was a word of the first set of three items", examples adapted from [23]). By contrast, K responses were to be given when the subjects felt confident concerning the recognition of an item but failed to evoke any specific conscious recollection from the learning sequence (e.g., for the item 'Road': "I feel I saw this word but could not find the exact feelings of when I saw the word, but I am sure that I saw it. I cannot find the background", example adapted from [23]). Subjects lacking confidence in a response could indicate it by means of Guess responses. Testing in this way ensured that $\mathrm{K}$ responses given by the subject actually reflected memory processes instead of level of uncertainty. Lastly, as done by Gardiner et al. [23], a procedure was performed to check whether the subjects could justify their R responses, proving that they had effectively relived the original event. Thus, for each $\mathrm{R}$ response provided, the subjects were invited to give contextual details from the original event, if they had not already provided them spontaneously (see [48] for further use of this score in dementias). These 'R justified' (RJ) responses refer to correct recognitions associated with $\mathrm{R}$ 
responses and with, at least, one detail relative to the context of encoding (thoughts, feelings or perceptions, associations of ideas, ...).

\subsection{Statistical analyses of behavioral data}

As the data were not normally distributed, neuropsychological scores of AD patients were compared to those of control subjects using non parametric Mann Whitney U tests. The Bonferoni correction was used to correct for multiple comparisons. For each score, alpha was stringently set at .007 , taking into account the 7 comparisons done (or $0.05 / 7 \sim 0.007$ ). In a second step, we performed Wilcoxon's tests on $\mathrm{R}$ and $\mathrm{K}$ responses in order to reveal the existence of a different effect of the kind of response ( $\mathrm{R} v s . \mathrm{K})$ according to the group.

\subsection{PET methodology}

All the patients underwent a resting PET study using $\left[{ }^{18} \mathrm{~F}\right]$ Fluoro-2-deoxy-D-glucose. Data were collected using the high-resolution PET device ECAT Exact HR+ with isotropic resolution of $4.6 \times 4.2 \times 4.2 \mathrm{~mm}$ (field of view $=158 \mathrm{~mm}$ ). The patients were fasted for at least 4 hours before scanning. The head was positioned on a headrest according to the canthomeatal line and gently restrained with straps. $\left[{ }^{18} \mathrm{~F}\right]$ Fluoro-2-deoxy-D-glucose uptake was measured in the resting condition, with eyes closed, in a quiet and dark environment. A catheter was introduced in a vein of the arm for radiotracer administration. Following ${ }^{68} \mathrm{Ga}$ transmission scans, 3-5 mCi of $\left[{ }^{18} \mathrm{~F}\right]$ Fluoro-2-deoxy-D-glucose were injected as a bolus at time 0 , and a 10 min PET data acquisition period was begun at 50 min post-injection. Sixtythree planes were acquired with septa out (volume acquisition), using a voxel size of $2.2 \times 2.2$ x $2.43 \mathrm{~mm}(\mathrm{x}, \mathrm{y}, \mathrm{z})$. During PET data acquisition, head motion was monitored continuously with laser beams. 
Actual glucose metabolic values in AD patients measured using PET may be underestimated because of brain atrophy, which accentuates the partial volume effect (PVE) on data collected. In order to avoid this bias, the PET data were corrected for PVE due to both cerebro-spinal fluid and white matter using the optimal voxel-by-voxel method originally proposed by Muller-Gartner et al. [41] with slight modifications proposed by Rousset et al. [55] and described in details in Quarantelli et al. [51].

Using statistical parametric mapping (SPM2; Wellcome Dept of Cognitive Neurology, London, UK), the PVE-corrected PET data were subjected to an affine and non-linear spatial normalization into the standard MNI PET template of SPM2, and to a reslicing of $2 \times 2 \times 2$ $\mathrm{mm}$. The spatially normalized sets were then smoothed with a $14 \mathrm{~mm}$ isotropic Gaussian filter to blur individual variations in gyral anatomy and to increase the signal-to-noise ratio. The "proportional scaling" routine was applied to the PVE-corrected PET data to control for individual variations in global CMRGlc. In order to minimize "edge effects" without excluding hypometabolic tissue in our AD patients, only the voxels with values $>40 \%$ of the mean for the whole brain were selected for the statistical analysis.

For the sake of completeness, we compared the normalized CMRGlc (nCMRGlc) data set obtained in our sample of $13 \mathrm{AD}$ patients with that obtained in another group of 20 healthy subjects (mean age $\pm \mathrm{SD}=63.2 \pm 8.5$ years). The influence of age was controlled by setting age as a confounding variable, and we used the uncorrected $\mathrm{p}<0.001(\mathrm{Z}>3.18)$ as cut-off for statistical significance. Table 1 shows the regions with significantly lower nCMRGlc in the group of $\mathrm{AD}$ patients, documenting hypometabolism in the precuneus and posterior cingulate gyrus bilaterally, as well as in the parietotemporal and the frontal areas bilaterally. This pattern of hypometabolism is in accordance with previous findings $[12,39,43]$. There was no significant reduction of CMRGlc values in medial temporal lobes, also in line with previous reports $[13,26]$. 
We then looked for correlations between the cognitive scores and resting nCMRGlc metabolism in the whole brain, using SPM and Pearson's correlation test. The influence of age and of the overall dementia severity was controlled by setting age and the MMSE score as confounding variables in a single linear regression. For each score, only the correlations in the neurobiologically expected direction were assessed, using a statistical threshold (uncorrected for multiple tests) of $\mathrm{p}<0.001$ for the voxels, to limit the number of statistical tests and the attending risk of false positives. Anatomical localization was according to both the labellized atlas ('toolbox aal') implemented in SPM2 and developed by Tzourio-Mazoyer et al. [65] and Talairach's Atlas, using M. Brett's set of linear transformations (see http://www.mrccbu.cam.ac.uk/Imaging/mnispace.html).

\subsection{Hypotheses}

We hypothesized that $\mathrm{AD}$ patients would be impaired in this recognition task and that recognition would be more based on a feeling of familiarity than on genuine episodic memory (i.e., more $\mathrm{K}$ responses and less $\mathrm{R}$ ones than controls). Concerning, the neural substrates of these alterations, based on neuroimaging studies carried out in healthy subjects, we hypothesized that correct recognitions associated with a $\mathrm{R}$ response would correlate with the metabolism of frontal $[17,69]$ and parietal areas [70] as well as medial temporal structures, notably the hippocampus ([32,69] and for review [72]). In contrast, recognitions associated with a $\mathrm{K}$ response would be linked to the metabolism of the cortex surrounding the hippocampus ([61,63] and for review [72]).

\section{Results}

\subsection{Behavioral data}


Mann Whitney U tests revealed that patients were significantly impaired on both delayed cued recall and recognition, albeit the difference did not survive the Bonferoni correction (Table 2). From a more qualitative point of view, AD patients also made more errors than healthy subjects as shown by a significant increase in false recognitions. These false recognitions are essentially recognitions of semantic distractors (Table 2). These analyses also revealed a significant effect of the group factor (controls $v s$. AD patients) on $\mathrm{R}$ responses $(\mathrm{p}<0.001)$, a trend for $\mathrm{K}$ responses $(\mathrm{p}<0.01)$, but no effect on $\mathrm{G}$ ones (Table 2 ). It is noteworthy that for $\mathrm{R}$ responses (and also for the number of false recognitions), all the patients exhibited performance lower than 1.65 standard deviation from the mean of healthy subjects. Thus, AD patients gave significantly fewer $\mathrm{R}$ responses and tended to give more $\mathrm{K}$ ones than controls. Then, Wilcoxon's tests were performed on R and K responses in order to reveal the existence of a different effect of response according to the group. Thus, we showed that elderly healthy subjects gave significantly more $R$ responses than $K$ ones $(p<0.01)$ while there was no significant difference between the percentage of $\mathrm{R}$ and $\mathrm{K}$ responses in $\mathrm{AD}$ group. Finally, AD patients also exhibited significantly poorer capacities to justify their R responses with details (RJ responses) about the learning context compared to controls (Table 2).

\subsection{Correlations between memory scores and nCMRGlc}

Since this study focuses on autonoetic consciousness, cognitivo-metabolic correlations were only searched for correct recognitions associated with a $\mathrm{R}$ response and compared to those associated with a $\mathrm{K}$ response.

The proportion of correct recognitions associated with $\mathrm{R}$ responses, relative to the total number of correct recognitions, was significantly and positively correlated to the metabolism of frontal areas in a bilateral and strikingly symmetric manner (Figures 1 and 2, and Table 3). 
In contrast, correct recognitions associated with $\mathrm{K}$ judgments, relative to the total number of correct recognitions, significantly and positively correlated with the metabolism of the parahippocampal gyrus and temporal neocortex, with a left predominance. Others correlations were also found in the left cuneus and the pre- and post-central gyri (Table 4 and Figures 3 and 4). Interestingly, even at a very liberal statistical threshold ( $<<0.05$ uncorrected), no significant correlation between frontal activity and $\mathrm{K}$ responses nor between the metabolism of the medial temporal lobes and $\mathrm{R}$ responses was found (data not shown).

\section{Discussion}

We will first discuss the neuropsychological performance and then turn near the neural substrates of the impairment of both autonoetic and noetic consciousness in mild AD.

\subsection{Behavioural data}

Delayed cued recall performance was lower in the group of patients, in line with previous studies who had demonstrated the sensitivity of delayed recall measures to AD (for review see [3,59]). Recognition performance also strongly decreased as testified by the decrease in correct responses and the significant increase in false recognitions, more particularly for semantic distractors. These poor performances reflect troubles from the encoding phase. AD patients encode and store an insufficient and unspecific representation of the items that does not enable them to characterize each word in an unique way and may result in confusion with other semantically-related items [25].

The patients gave significantly less $\mathrm{R}$ responses and tended to give more $\mathrm{K}$ ones than controls. These results are in agreement with those reported by Dalla Barba [9] showing a decrease in $\mathrm{R}$ responses during free and forced-choice recognition tasks. A diminution of $\mathrm{R}$ responses has also been observed in mild AD patients during an autobiographical memory 
task [48]. The high number of $\mathrm{K}$ responses suggests that recognition is more based on a feeling of familiarity than in controls and concurs with the observation of preserved familiarity processes contrasting with the alteration of recollection in $\mathrm{AD}[22,35]$. These results are also in line with the disruption of recollection reported in patients with medial temporal lobe amnesia [2,66,71], medial temporal lobes being the area earliest and most severely affected by neuropathological lesions in $\mathrm{AD}[4,10]$.

$\mathrm{RJ}$ responses ( $\mathrm{R}$ responses justified by details about the encoding context) are a useful measure to better understand the phenomenon of recollection because they prove the existence of the mental travel in time permitting the retrieval of contextual details. Noteworthy, AD patients presented an altered autonoetic consciousness (significant reduction in $\mathrm{R}$ responses) and gave very few RJ responses highlighting their major difficulties to recollect contextual details. This result is in line with those obtained using notably the DRM paradigm, that enables to produce high levels of false recognition or recall of a critical nonpresented word by presenting to subjects lists of words in which every item is an associate of the critical non-presented word, and demonstrating recollection deficits in AD patients [22]. Since patients are unable to retrieve the specific learning context of an item, they may thus mistake it for a semantically-linked item on the basis of a feeling of familiarity explaining the increase in false recognitions in the group of $\mathrm{AD}$ patients compared to elderly controls.

\subsection{Neural substrates of the impairment of consciousness in mild AD}

As recognition can be made either by re-experiencing the learning episode or on the basis on a feeling of familiarity, we focused our analysis of PET data on correct recognitions associated with $\mathrm{R}$ or $\mathrm{K}$ responses, reflecting the involvement of autonoetic and noetic consciousness respectively. Significant positive correlations between correct recognitions associated with $\mathrm{K}$ responses and CMRGlc were found mainly in the parahippocampal and the 
lateral temporal cortices, in line with previous studies $([8,63]$ and for review see [61]), confirming that familiarity judgments are mainly subserved by the cortex surrounding the hippocampus. In contrast, correct recognitions associated with $\mathrm{R}$ responses correlated with the frontal cortex bilaterally (mainly Brodmann area 10). One may hypothesize that the correlation between $\mathrm{R}$ responses and the metabolism of frontal areas is modulated by another variable such as an executive dysfunction. Nevertheless, this assumption appears unlikely since a new correlation analysis setting a measure of executive functions (backward digit span) as confounding variable yielded similar results (data not shown). This result indicates that the correlation with frontal areas is not related to an executive dysfunction nor to overall severity of dementia, since all correlations were searched setting the MMSE score as confounding variable, but actually reflects the impairment of autonoetic consciousness.

The correlation with frontal areas is in line with other studies obtained with various methodological approaches. Thus, it has been shown that patients with frontal lesions present deficits during source (or contextual) memory tasks, thought to rely mainly on recollection [30,52]. In the same way, frontal dysfunction also induce reductions in $\mathrm{R}$ judgments during episodic [36] and autobiographical [50] memory tasks. Event-related potentials studies have also strengthen the role of frontal areas in recollection since $\mathrm{R}$ responses have been consistently associated with a late frontal positivity ([16,17] and for review see [56]). This correlation with frontal areas may reflect the involvement of monitoring processes in recognition tasks [7] as well as effortful retrieval [58] and successful recollection [27] processes. Based on these arguments, we suggest that the recruitment of frontal areas, particularly involved in effortful and monitoring processes, may be a crucial step in the initiation of the process of recollection.

Other studies carried out in healthy subjects suggested that the frontal cortex is not the only area involved in recollection and that medial temporal lobe structures, notably the 
hippocampus, may also take part to this phenomenon (for review see [61], but see also [37] for divergent findings). Thus, Ranganath et al. [53] have demonstrated that neural activity in the rhinal cortex during encoding predicts subsequent familiarity-based recognition whereas activity in the hippocampus and posterior parahippocampal cortex selectively predicts recollection (associated with autonoetic consciousness). Episodic memories are composed of several elements (event, perceptions, smells,...) stored in various cortical areas, but all linked by the hippocampus that serves as an index to retrieve all the facets of the memory $[20,42,49,60]$. The fact that we do not report any significant correlation between $\mathrm{R}$ responses and the metabolism of the hippocampus might suggest that $\mathrm{AD}$ patients do not recollect contextual details and only have the subjective feeling of reliving the event, i.e. 'sense of pastness' but no recollection of the episodic details. This suggestion is supported by the difficulties of $\mathrm{AD}$ patients to justify their $\mathrm{R}$ judgments with specific details of the encoding context. Our results are also corroborated by an observation reported by Budson and colleagues [5,6] who demonstrated, using an adaptation of the DRM paradigm, that AD patients were unable to suppress their false recognitions over trials due to an inability to develop any item-specific recollection. We suggest that frontal areas may subserve this impression of reliving the original event (i.e., autonoetic consciousness) but not the access to contextual elements per se.

We do not report any significant correlation with parietal areas that are generally activated during recollection (e.g., [18,27,70,73] and for review [67]). Our data suggest therefore that the dysfunction of frontal areas explains to a large extent the impairment of autonoetic consciousness observed in our group of AD patients. Nevertheless, as suggested by the literature in healthy subjects, we cannot exclude than other brain areas are also involved in the disruption of autonoetic consciousness in AD. 
On a more clinical point of view, our results extend our knowledge of the neural substrates of memory impairment in $\mathrm{AD}$ by focusing on more subtle measures of memory performance and targeting specific cognitive components. Such investigations should also provide a detailed analysis of residual abilities, which could be then used to help patients in their everyday life activities despite their anterograde amnesia. Indeed, therapeutic strategies in $\mathrm{AD}$ patients designed to increase dependence on familiarity-based memory in daily living may help to cope, at least in the early stages of the disease, with the consequences of memory decline [68]. In addition, as autonoetic consciousness is critical to shape one's own identity and a feeling of continuity, data about recollection and familiarity processes could also inform us on the interest of further investigations on self awareness, often impaired in AD [1], by means of autobiographical memory tasks for example.

To conclude, we have shown that $\mathrm{AD}$ patients presented poor recognition performances linked, in part, to an alteration of autonoetic consciousness and to major difficulties to reinstate the context in which information was encoded. Using voxel-based mapping of the correlations between memory performance and resting-state cerebral metabolism measured by PET, we have shown that their impairment of autonoetic consciousness is mainly subserved by the dysfunction of frontal areas. This result suggests that frontal areas are crucial in the subjective feeling of reliving an event (i.e. "reliving" component of episodic memory). However, since $\mathrm{AD}$ patients were unable to justify their $\mathrm{R}$ responses with details concerning the context of encoding (other than the cue given by the experimenter), we suggest that frontal areas together with, at least, medial temporal lobes and parietal areas, may be necessary to achieve a genuine episodic recollection comprising the event itself, the mental travel in time and phenomenological details. In addition, as frontal areas are particularly involved in monitoring processes during recognition tasks [7], effortful retrieval [58] and successful recollection [27], we suggest that a dysfunction, even subtle, of these areas may disrupt the 
effortful process of research in memory that is critical to enable a subject to have access, in a second step, to the contextual details of a memory. These results remain nevertheless to be confirmed on a larger sample of patients using, for example, event-related fMRI. 
Acknowledgments : The authors want to thank the cyclotron staff, G. Chételat, C. Gyri, G. Kalpouzos, Dr. F. Le Doze, N. Loisel, M-H Noël, M-C Onfroy for their help in this study. Géraldine Rauchs was supported by the Association France Alzheimer.

Disclosure statement: All authors disclose no conflict of interest with other people or organizations within three years of beginning the present work. 


\section{References}

[1] Addis DR, Tippett LJ. Memory of myself: autobiographical memory and identity in Alzheimer's disease. Memory 2004; 12(1):56-74.

[2] Aggleton JP, Vann SD, Denby C, Dix S, Mayes AR, Roberts N, Yonelinas AP. Sparing of the familiarity component of recognition memory in a patient with hippocampal pathology. Neuropsychologia 2005; 43(12):1810-23.

[3] Albert MS. Cognitive and neurobiologic markers of early Alzheimer disease. Proc Natl Acad Sci U S A 1996; 93(24):13547-51.

[4] Braak H, Braak E. Neuropathological stageing of Alzheimer-related changes. Acta Neuropathol (Berl) 1991; 82(4):239-59.

[5] Budson DA, Daffner KR, Desikan R, Schacter DL. When false recognition is unopposed by true recognition: Gist-based memory distortion in Alzheimer's disease. Neuropsychology $2000 ; 14(2): 277-87$

[6] Budson AE, Sitarski J, Daffner KR, Schacter DL. False recognition of pictures versus words in Alzheimer's disease: the distinctiveness heuristic. Neuropsychology 2002; 16(2):163-73.

[7] Cabeza, R., Locantore, J.K., \& Anderson, N.D. Lateralization of prefrontal activity during episodic memory retrieval: evidence for the production-monitoring hypothesis. J Cogn Neurosci 2003; 15(2):249-59.

[8] Cabeza R, Daselaar SM, Dolcos F, Prince SE, Budde M, Nyberg L. Task-independent and task-specific age effects on brain activity during working memory, visual attention and episodic retrieval. Cereb Cortex 2004; 14(4): 364-75. 
[9] Dalla Barba G. Recognition memory and recollective experience in Alzheimer's disease. Memory 1997; 5(6):657-72.

[10] Delacourte A, David JP, Sergeant N, Buée L, Wattez A, Vermersch P, Ghozali F, FalletBianco C, Pasquier F, Lebert F, Petit H, Di Menza C. The biochemical pathway of neurofibrillary degeneration in aging and Alzheimer's disease. Neurology 1999; 52(6):115865.

[11] Deese J. On the prediction of occurrence of particular verbal intrusions in immediate recall. J Exp Psychol 1959, 58(1):17-22.

[12] Demetriades AK. Functional neuroimaging in Alzheimer's type dementia. J Neurol Sci $2002 ; 15: 247-51$

[13] Desgranges B, Baron JC, de la Sayette V, Petit-Taboué MC, Benali K, Landeau B, Lechevalier B, Eustache F. The neural substrates of memory systems impairment in Alzheimer's disease. A PET study of resting brain glucose utilization. Brain 1998; 121(Pt4):611-31.

[14] Desgranges B, Baron JC, Lalevée C, Giffard B, Viader F, de la Sayette V, Eustache F. The neural substrates of episodic memory impairment in Alzheimer's disease as revealed by FDG-PET: relationship to degree of deterioration. Brain 2002; 125(Pt5):1116-24.

[15] Desgranges, B., Baron, J.C., Giffard, B., Chételat, G., Lalevée, C., Viader, F., de la Sayette V, Eustache F. The neural basis of intrusions in free recall and cued recall: a PET study in Alzheimer's disease. NeuroImage 2002; 17(3):1658-64. 
[16] Duarte A, Ranganath C, Winward L, Hayward D, Knight RT. Dissociable neural correlates for familiarity and recollection during the encoding and retrieval of pictures. Brain Res Cogn Brain Res 2004; 18(3): 255-72.

[17] Düzel E, Yonelinas AP, Mangun GR, Heinze HJ, Tulving E. Event-related brain potential correlates of two states of conscious awareness in memory. Proc Natl Acad Sci USA 1997; 94(11): 5973-78.

[18] Eldridge LL, Knowlton BJ, Furmanski CS, Bookheimer SA, Engel SA. Remembering episodes: a selective role for the hippocampus during retrieval. Nat Neurosci 2000; 3(11):1149-52.

[19] Eustache F, Desgranges B, Giffard B, de la Sayette V, Baron JC. Entorhinal cortex disruption causes memory deficit in early Alzheimer's disease as shown by PET. NeuroReport $2001 ; 12(4): 683-85$.

[20] Eustache F, Piolino P, Giffard B, Viader F, de la Sayette V, Baron JC, Desgranges B. In the course of time': a PET study of the cerebral substrates of autobiographical amnesia in Alzheimer's disease. Brain 2004; 127(Pt7):1549-60.

[21] Folstein MF, Folstein SE, McHugh PR. "Mini-mental state". A practical method for grading the cognitive state of patients for the clinician. J Psychiatr Res 1975; 12(3):189-98.

[22] Gallo DA, Sullivan AL, Daffner KR, Schacter DL, Budson AE. Associative recognition in Alzheimer's disease: evidence for impaired recall-to-reject. Neuropsychology 2004; 18(3): $556-63$

[23] Gardiner JM, Ramponi C, Richardson-Klavehn A. Experiences of remembering, knowing, and guessing. Conscious Cogn 1998; 7(1):1-26. 
[24] Giffard B, Desgranges B, Nore-Mary F, Lalevée C, de la Sayette V, Pasquier F, Eustache

F. The nature of semantic memory deficits in Alzheimer's disease: New insights from hyperpriming effects. Brain 2001; 124:1522-32.

[25] Grober E, Buschke H. Genuine memory deficits in dementia. Dev Neuropsychol 1987; 3:13-36.

[26] Herholz K, Salmon E, Perani D, Baron JC, Holthoff V, Frolich L, Schonknecht P, Ito K, Mielke R, Kalbe E, et al. Discrimination between Alzheimer dementia and controls by automated analysis of multicenter FDG PET. NeuroImage 2002; 17(1):302-16.

[27] Henson RN, Rugg MD, Shallice T, Josephs O, Dolan RJ. Recollection and familiarity in recognition memory: an event-related functional magnetic resonance imaging study. J Neurosci 1999; 19(10):3962-72.

[28] Hirono N, Mori E, Ishii K, Imamura T, Tanimukai S, Kazui H, Hashimoto M, Takatsuki Y, Kitagaki H, Sasaki M. Neuronal substrates for semantic memory: a positron emission tomography study in Alzheimer's disease. Dement Geriatr Cogn Disord 2001; 12(1):15-21.

[29] Jacoby LL. A process dissociation framework: Separating automatic from intentional uses of memory. Journal of Memory and Language 1991; 30:513-41.

[30] Janowsky JS, Shimamura AP, Squire LR. Source memory impairment in patients with frontal lobe lesions. Neuropsychologia 1989; 27(8):1043-56.

[31] Knight RG. Controlled and automatic memory process in Alzheimer's disease. Cortex $1998 ; 34(3): 427-35$.

[32] Knowlton BJ. The relationship between remembering and knowing: a cognitive neuroscience perspective. Acta Psychol (Amst) 1998; 98(2-3):253-65. 
[33] Koivisto M, Portin R, Seinelä A, Rinne J. Automatic influences of memory in Alzheimer's disease. Cortex 1998; 34(2):209-19.

[34] Lekeu F, Van der Linden M, Chicherio C, Collette F, Degueldre C, Franck G, Moonen G, Salmon E. Brain correlates of performance in a free/cued recall task with semantic encoding in Alzheimer disease. Alzheimer Dis Assoc Disord 2003; 17(1):35-45.

[35] Lekeu F, Van der Linden M, Degueldre C, Lemaire C, Luxen A, Franck G, Moonen G, Salmon E. Effects of Alzheimer's disease on the recognition of novel versus familiar words: neuropsychological and clinico-metabolic data. Neuropsychology 2003; 17(1):143-54.

[36] Levine B, Black SE, Cabeza R, Sinden M, McIntosh AR, Toth JP, Tulving E, Stuss DT. Episodic memory and the self in a case of isolated retrograde amnesia. Brain 1998; 121(Pt10):1951-73.

[37] Manns JR, Hopkins RO, Reed JM, Kitchener EG, Squire LR. Recognition memory and the human hippocampus. Neuron 2003; 37(1): 171-80.

[38] McKhann G, Drachman D, Folstein M, Katzman R, Price D, Stadlan EM. Clinical diagnosis of Alzheimer's disease: report of the NINCDS-ADRDA Work Group under the auspices of Department of Health and Human Services Task Force on Alzheimer's Disease. Neurology 1984; 34(7):939-44.

[39] Minoshima S, Foster NL, Kuhl DE. Posterior cingulate cortex in Alzheimer's disease. Lancet 1994; 344(8926):895.

[40] Morris RG. The cognitive neuropsychology of Alzheimer-type dementia. New York: Oxford University Press; 1996. 
[41] Muller-Gartner HW, Links JM, Prince JL, Bryan RN, McVeigh E, Leal JP, Davatzikos

C, Frost JJ. Measurement of radiotracer concentration in brain gray matter using positron emission tomography: MRI-based correction for partial volume effects. J Cereb Blood Flow Metab 1992; 12(4):571-83.

[42] Nadel L, Moscovitch M. Memory consolidation, retrograde amnesia and the hippocampal complex. Curr Opin Neurobiol 1997; 7(2):217-27.

[43] Nestor PJ, Scheltens P, Hodges JR. Advances in the early detection of Alzheimer's disease. Nat Med 2004; 10: S34-S41.

[44] Nestor PJ, Fryer TD, Hodges JR. Declarative memory impairments in Alzheimer's disease and semantic dementia. NeuroImage, in press.

[45] Newberg A, Cotter A, Udeshi M, Brinkman F, Glosser G, Alavi A, Clark C. Brain metabolism in the cerebellum and visual cortex correlates with neuropsychological testing in patients with Alzheimer's disease. Nucl Med Commun 2003; 24(7):785-90.

[46] Perani D, Bressi S, Cappa SF, Vallar G, Alberoni M, Grassi F, Caltagirone C, Cipolotti L, Franceschi M, Lenzi GL, et al. Evidence of multiple memory systems in the human brain. A [18F]FDG PET metabolic study. Brain 1993; 116:903-19.

[47] Petersen RC, Smith GE, Ivnik RJ, Kokmen E, Tangalos EG. Memory function in very early Alzheimer's disease. Neurology 1994; 44(5):867-82.

[48] Piolino P, Desgranges B, Belliard S, Matuszewski V, Lalevée C, de la Sayette V, Eustache F. Autobiographical memory and autonoetic consciousness: triple dissociation in neurodegenerative diseases. Brain 2003; 126(Pt10):2203-19. 
[49] Piolino P, Giffard-Quillon G, Desgranges B, Chételat G, Baron JC, Eustache F. Reexperiencing old memories via hippocampus: a PET study of autobiographical memory. NeuroImage 2004; 22(3):1371-83.

[50] Piolino P, Hannequin D, Desgranges B, Girard C, Beaunieux H, Giffard B, Lebreton K, Eustache F. Right ventral frontal hypometabolism and abnormal sense of self in a case of disproportionate retrograde amnesia. Cognitive Neuropsychology 2005; 22(8):1005-34.

[51] Quarantelli M, Berkouk K, Prinster A, Landeau B, Svarer C, Balkay L, Alfano B, Brunetti A, Baron JC, Salvatore M. Integrated software for the analysis of brain PET/SPECT studies with partial-volume-effect correction. J Nucl Med 2004; 45(2):192-201.

[52] Ranganath C, Knight RT. Prefrontal cortex and episodic memory: integrating findings from neuropsychology and functional brain imaging. In: Parker A, Wilding E, Bussey T, editors. The cognitive neuroscience of memory encoding and retrieval. Philadelphia: Psychology Press; 2003, p. 83-99.

[53] Ranganath C, Yonelinas AP, Cohen MX, Dy CJ, Tom SM, D’Esposito M. Dissociable correlated of recollection and familiarity within the medial temporal lobes. Neuropsychologia $2003 ; 42: 2-13$.

[54] Roediger HL III, McDermott KB. Creating false memories: remembering words not presented in lists. J Exp Psychol Learn Mem Cogn 1995; 21(4):803-14.

[55] Rousset OG, Ma Y, Evans AC. Correction for partial volume effects in PET: principle and validation. J Nucl Med 1998; 39(5):904-11.

[56] Rugg MD, Yonelinas AP. Human recognition memory: a cognitive neuroscience perspective. Trends Cogn Sci 2003; 7(7):313-19. 
[57] Salmon E, Lespagnard S, Marique P, Peeters F, Herholz K, Holthoff V, Kalbe E, Anchisi

D, Adam S, Collette F, Garraux G. Cerebral metabolic correlates of four dementia scales in Alzheimer's disease. J Neurol 2005; 252(3):283-90.

[58] Schacter DL, Savage CR, Alpert NM, Rauch SL, Albert MS. The role of hippocampus and frontal cortex in age-related memory changes: a PET study. NeuroReport 1996; 7(6):1165-69.

[59] Soininen HS, Scheltens P. Early diagnostic indices for the prevention of Alzheimer's disease. Ann Med 1998; 30(6):553-59.

[60] Squire LR, Alvarez P. Retrograde amnesia and memory consolidation: a neurobiological perspective. Curr Opin Neurobiol 1995, 5(2):169-77.

[61] Squire LR, Stark CEL, Clark RE. The medial temporal lobe. Annu Rev Neurosci 2004; 27:279-306.

[62] Tulving E. How many memory systems are there? Am Psychol 1985; 40:385-98.

[63] Tulving E, Markowitsch HJ. Episodic and declarative memory: role of the hippocampus. Hippocampus 1998; 8(3):198-204.

[64] Tulving E. Episodic memory: from mind to brain. Annu Rev Psychol 2002; 53:1-25.

[65] Tzourio-Mazoyer N, Landeau B, Papathanassiou D, Crivello F, Etard O, Delcroix N, Mazoyer B, Joliot M. Automated anatomical labeling of activations in SPM using a macroscopic anatomical parcellation of the MNI MRI single-subject brain. NeuroImage 2002; 15(1):273-89. 
[66] Verfaellie M, Treadwell JR. The status of recognition memory in amnesia. Neuropsychology 1993; 7(1):5-13.

[67] Wagner AD, Shannon BJ, Kahn I, Buckner RL. Parietal lobe contributions to episodic memory retrieval. Trends Cogn Sci 2005; 9(9):445-53.

[68] Westerberg CE, Paller KA, Weintraub S, Mesulam M-Marsel, Holdstock JS, Mayes AR, Reber PJ. When memory does not fail: familiarity-based recognition in mild cognitive impairment and Alzheimer's disease. Neuropsychology 2006; 20(2):193-205.

[69] Wheeler MA, Stuss DT, Tulving E. Toward a theory of episodic memory: the frontal lobes and autonoetic consciousness. Psychol Bull 1997; 121(3):331-54.

[70] Wheeler ME, Buckner RL. Functional-anatomic correlates of remembering and knowing. NeuroImage $2004 ; 21(4): 1337-49$.

[71] Yonelinas AP, Kroll NE, Dobbins I, Lazzara M, Knight RT. Recollection and familiarity deficits in amnesia: convergence of remember-know, process dissociation, and receiver operating characteristic data. Neuropsychology 1998; 12(3):323-39.

[72] Yonelinas AP. The nature of recollection and familiarity: a review of 30 years of research. J Mem Lang 2002; 46:441-517.

[73] Yonelinas AP, Otten LJ, Shaw KN, Rugg MD. Separating the brain regions involved in recollection and familiarity in recognition memory. J Neurosci 2005; 25(11):3002-8. 


\section{Figure captions}

Table 1:

The influence of age was controlled by setting age as a confounding variable, and we used the uncorrected $\mathrm{p}<0.001(\mathrm{Z}>3.18)$ as cut-off for statistical significance. BA: Brodmann area; $\mathrm{x}$, $y, z$ : MNI space stereotactic coordinates of the peak in mm; L: left; R: Right; $n=13$ for AD patients; $\mathrm{n}=20$ for healthy elderly subjects. Significant $\mathrm{P}<0.001$, uncorrected.

Table 2:

Neuropsychological data in the AD group were compared to those obtained in the group of ten elderly control subjects, using non parametric Mann-Whitney U tests, and were corrected for multiple comparisons using Bonferoni correction.

Table 3:

BA: Brodmann area; $\mathrm{x}, \mathrm{y}, \mathrm{z}$ : MNI space stereotactic coordinates of the peaks in mm; L: left; R: Right. The clusters are listed in decreasing order of peak Z-score. Significant $\mathrm{P}<0.001$, uncorrected.

Table 4:

BA: Brodmann area; $\mathrm{x}, \mathrm{y}, \mathrm{z}$ : MNI space stereotactic coordinates of the peaks in mm; L: left; R: Right. The clusters are listed in decreasing order of peak Z-score. Significant $\mathrm{P}<0.001$, uncorrected.

Figure 1:

SPM2 surface rendering depicting in red the significant $(\mathrm{P}<0.001$, uncorrected $)$ clusters of significant positive correlations, in $13 \mathrm{AD}$ patients, between the proportion of correct 
recognitions associated with a $\mathrm{R}$ judgment and nCMRGlc (normalized resting-state cerebral metabolic rates of glucose), controlling for the confounding effect of age and of dementia severity (MMSE score), projected on a standard T1-weighted MRI for anatomical orientation, according to six views indicated on the side of each image.

Figure 2: Scatter plots of the correlations between nCMRGlc values and the proportion of correct recognitions associated with a $\mathrm{R}$ judgment, in left (-32 54 2) and right (30 54 10) frontal areas.

Figure 3: Results from SPM2 analysis: positive correlations ( $\mathrm{P}<0.001$ uncorrected, SPM maps thresholded at $Z>3.26$ ) between the proportion of correct recognitions associated with a $K$ response and nCMRGlc controlling for the confounding effect of age and of dementia severity (MMSE score). For anatomical orientation, the significant correlations are shown as coloured voxels superimposed on a normal MRI set spatially normalized on the Montreal Neurological Institute (MNI) template. The MRI set has been cut out to show only the analysed voxels, i.e. in which nCMRGlc was $>40 \%$ of mean nCMRGlc across all patients. The right side of the figure corresponds to the right hemisphere.

Figure 4: Example of a scatter plot of the correlations between nCMRGlc values and the number of correct recognitions associated with a $\mathrm{K}$ response in the left parahippocampal gyrus (-22-14 -26). 
Table 1: Significant decreases in normalized regional metabolic activity in AD patients compared with healthy subjects.

\begin{tabular}{|c|c|c|c|c|c|c|c|}
\hline \multicolumn{2}{|c|}{ Regions } & \multirow{2}{*}{$\begin{array}{c}\begin{array}{c}\text { Cluster size } \\
\text { (no. of voxels) }\end{array} \\
1740\end{array}$} & \multirow{2}{*}{$\begin{array}{c}\text { BA } \\
7 / 31 / 19\end{array}$} & \multirow{2}{*}{$\begin{array}{l}x \\
8\end{array}$} & \multirow{2}{*}{$\begin{array}{c}y \\
-52\end{array}$} & \multirow{2}{*}{$\begin{array}{c}z \\
30\end{array}$} & \multirow{2}{*}{$\begin{array}{c}Z \\
5.3\end{array}$} \\
\hline $\begin{array}{l}R \\
L \\
R \\
L \\
L \\
L \\
R \\
R\end{array}$ & $\begin{array}{l}\text { precuneus } \\
\text { precuneus } \\
\text { middle cingulate gyrus } \\
\text { posterior cingulate gyrus } \\
\text { cuneus } \\
\text { middle cingulate gyrus } \\
\text { posterior cingulate gyrus } \\
\text { cuneus }\end{array}$ & & & & & & \\
\hline $\begin{array}{l}\mathrm{L} \\
\mathrm{L}\end{array}$ & $\begin{array}{l}\text { inferior temporal gyrus } \\
\text { middle temporal gyrus }\end{array}$ & 302 & $20 / 21$ & -50 & 14 & -40 & 4.58 \\
\hline $\begin{array}{l}\mathrm{L} \\
\mathrm{L}\end{array}$ & $\begin{array}{l}\text { inferior parietal gyrus } \\
\text { angular gyrus }\end{array}$ & 539 & 40 & -36 & -54 & 42 & 4.24 \\
\hline $\begin{array}{l}\mathrm{L} \\
\mathrm{L} \\
\mathrm{L} \\
\mathrm{L}\end{array}$ & $\begin{array}{l}\text { insula } \\
\text { superior temporal gyrus } \\
\text { Heschl gyrus } \\
\text { rolandic operculum }\end{array}$ & 478 & $22 / 42$ & -38 & -16 & 8 & 4.22 \\
\hline $\begin{array}{l}R \\
R \\
R\end{array}$ & $\begin{array}{l}\text { angular gyrus } \\
\text { inferior parietal gyrus } \\
\text { supramarginal gyrus }\end{array}$ & 1340 & 40 & 48 & -62 & 46 & 4.10 \\
\hline $\begin{array}{l}\mathrm{R} \\
\mathrm{R}\end{array}$ & $\begin{array}{l}\text { middle frontal gyrus } \\
\text { inferior frontal gyrus }\end{array}$ & 84 & 11 & 28 & 46 & -18 & 3.48 \\
\hline $\begin{array}{l}\mathrm{L} \\
\mathrm{L}\end{array}$ & $\begin{array}{l}\text { superior temporal gyrus } \\
\text { supramarginal gyrus }\end{array}$ & 35 & $42 / 22$ & 54 & -32 & 20 & 3.40 \\
\hline $\begin{array}{l}\mathrm{L} \\
\mathrm{L}\end{array}$ & $\begin{array}{l}\text { middle frontal gyrus } \\
\text { inferior frontal gyrus }\end{array}$ & 41 & 10 & -32 & 48 & 2 & 3.37 \\
\hline
\end{tabular}


Table 2: Neuropsychological performance of the AD patients and elderly controls.

\begin{tabular}{|c|c|c|c|c|}
\hline \multirow[t]{2}{*}{ Neuropsychological score } & \multicolumn{2}{|c|}{ Alzheimer's patients } & \multicolumn{2}{|c|}{ Elderly controls } \\
\hline & Mean $\pm S D$ & Median (range) & Mean $\pm S D$ & Median (range) \\
\hline Delayed cued recall (max 15) & $10.1 \pm 3.7 \quad$ (a) & $10(4-15)$ & $14.7 \pm 0.7$ & $15(13-15)$ \\
\hline Correct recognitions ( $\max 15)$ & $12.8 \pm 2.3$ & $14(9-15)$ & $14.6 \pm 0.7$ & $15(13-15)$ \\
\hline False recognitions & $7 \pm 4.4^{* * *}$ & $6(1-17)$ & $0.2 \pm 0.4$ & $0(0-1)$ \\
\hline$-\%$ of FR for semantic distractors & 82.9 & $\mathrm{x}$ & 100 & $\mathrm{x}$ \\
\hline - \% of FR for neutral distractors & 17.1 & $\mathrm{x}$ & 0 & $\mathrm{x}$ \\
\hline$\%$ of $\mathrm{R}$ responses (on correct recognitions) & $44.1 \pm 32.6^{* * *}$ & $33.3(0-100)$ & $94 \pm 5.8$ & $93.3(86.6-100)$ \\
\hline$\%$ of $\mathrm{K}$ responses (on correct recognitions) & $38 \pm 34.4(a)$ & $22.2(0-100)$ & $3.5 \pm 4.8$ & $0(0-13.3)$ \\
\hline$\%$ of $\mathrm{G}$ responses (on correct recogntions) & $11.6 \pm 18.1$ & $0(0-55.5)$ & $0.7 \pm 2.1$ & $0(0-6.6)$ \\
\hline$\%$ of $\mathrm{RJ}$ responses (on correct recognitions) & $1.1 \pm 2.7^{* \star *}$ & $0(0-7.7)$ & $39.3 \pm 27.4$ & $40(0-78.6)$ \\
\hline
\end{tabular}

$<0.001$, corrected for multiple comparisons.

(a) $: p<0.01$ 
Table 3: Peaks of significant correlations between the proportion of correct recognitions associated with a $\mathbf{R}$ response and nCMRGlc.

\begin{tabular}{|c|c|c|c|c|c|c|}
\hline Region & $\begin{array}{c}\text { Cluster size } \\
\text { (number of voxels) }\end{array}$ & BA & $x$ & $y$ & $z$ & Z \\
\hline $\begin{array}{l}\text { L middle frontal gyrus } \\
L \text { superior frontal gyrus } \\
L \text { frontal superior orbital gyrus } \\
L \text { frontal middle orbital gyrus }\end{array}$ & 1428 & 10 & -32 & 54 & 2 & 4.72 \\
\hline $\begin{array}{l}R \text { middle frontal gyrus } \\
R \text { superior frontal gyrus } \\
R \text { frontal superior orbital gyrus } \\
R \text { frontal middle orbital gyrus }\end{array}$ & 1190 & 10 & 30 & 54 & 10 & 4.47 \\
\hline $\begin{array}{l}\mathrm{R} \text { median superior frontal gyrus } \\
\mathrm{R} \text { superior frontal gyrus }\end{array}$ & 96 & 8 & 14 & 50 & 44 & 4.27 \\
\hline $\begin{array}{l}\mathrm{L} \text { frontal inferior orbital gyrus } \\
\mathrm{L} \text { frontal middle orbital gyrus }\end{array}$ & 44 & 47 & -48 & 46 & -14 & 3.33 \\
\hline
\end{tabular}


Table 4: Peaks of significant correlations between the proportion of correct recognitions associated with a K judgment and nCMRGlc.

\begin{tabular}{lcccccc}
\hline \multicolumn{1}{c}{ Region } & $\begin{array}{c}\text { Cluster size } \\
\text { (number of voxels) }\end{array}$ & BA & $\mathrm{x}$ & $\mathrm{y}$ & $\mathrm{z}$ & $\mathrm{Z}$ \\
\hline $\begin{array}{l}\text { L parahippocampal gyrus } \\
\text { L Hippocampus }\end{array}$ & 232 & $28 / 36$ & -22 & -14 & -26 & 3.96 \\
$\begin{array}{l}\text { L fusiform gyrus } \\
\text { L postcentral gyrus }\end{array}$ & 47 & $3 / 4$ & -24 & -32 & 56 & 3.88 \\
$\begin{array}{l}\text { L precentral gyrus } \\
\text { R temporal pole: middle temporal gyrus }\end{array}$ & 20 & 38 & 24 & 14 & -36 & 3.36 \\
$\begin{array}{l}\text { R temporal pole: superior temporal gyrus } \\
\text { R postcentral gyrus }\end{array}$ & 45 & 4 & 16 & -26 & 62 & 3.35 \\
$\begin{array}{l}\text { R precentral gyrus } \\
\text { R temporal inferior gyrus } \\
\text { L calcarine region }\end{array}$ & 20 & 20 & 50 & -30 & -32 & 3.31 \\
L cuneus & 46 & 18 & -10 & -78 & 16 & 3.26 \\
\hline
\end{tabular}


Rauchs et al.

Figure 1:

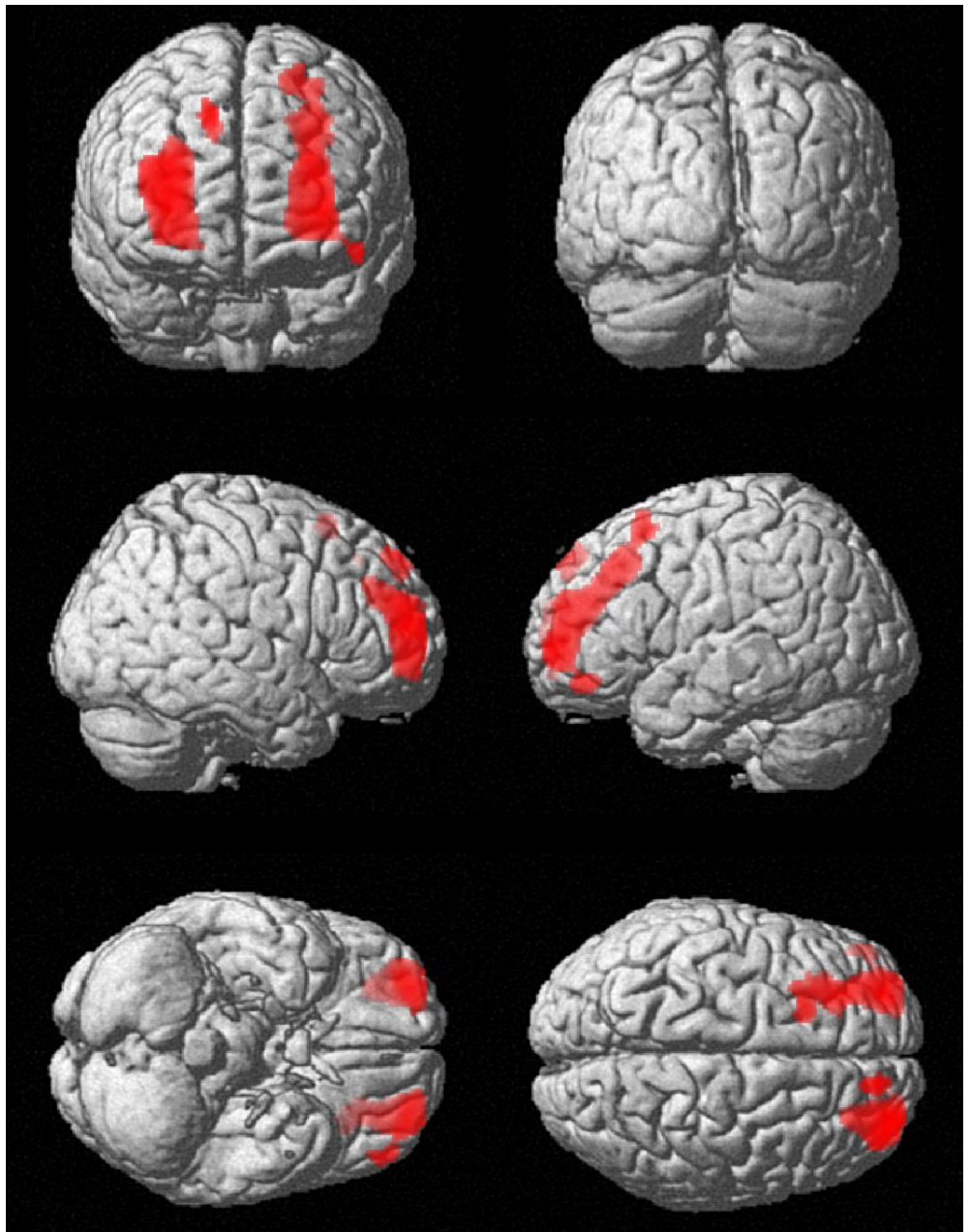


Figure 2 :

L frontal areas [-32 542$]$

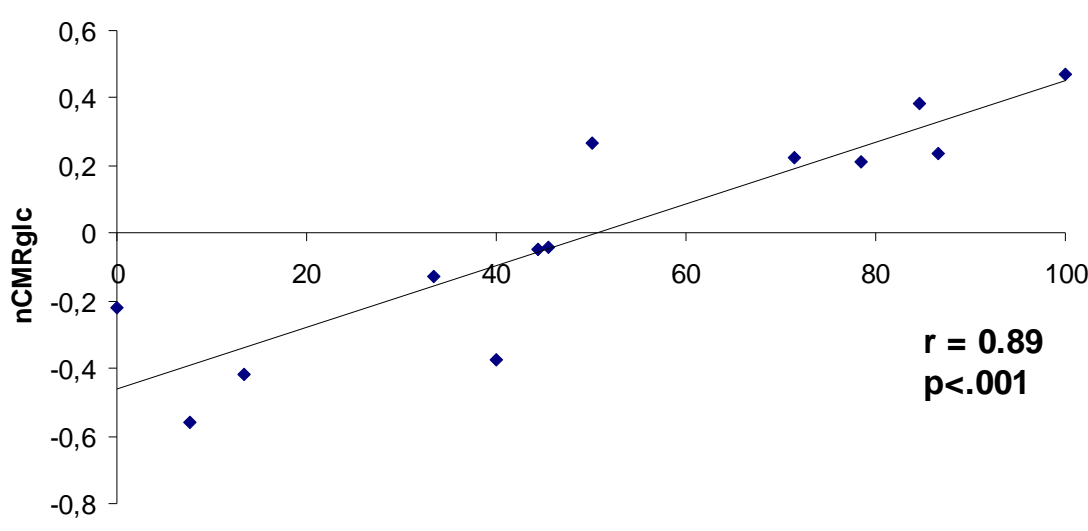

Percentage of correct recognitions associated with a $\mathrm{R}$ response

\section{$R$ frontal areas [30 54 10]}

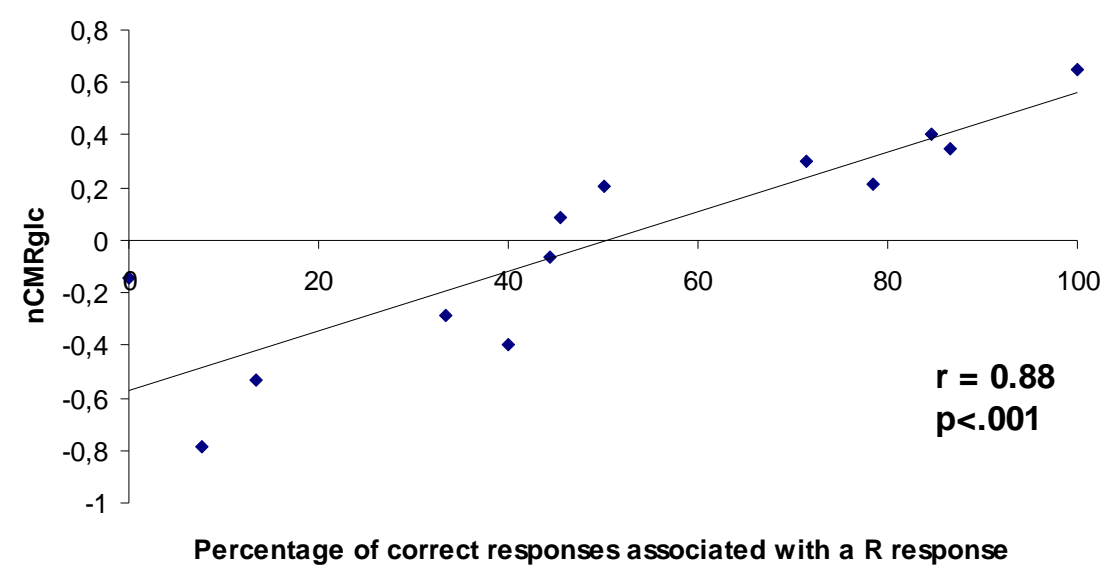


Rauchs et al.

Figure 3 :

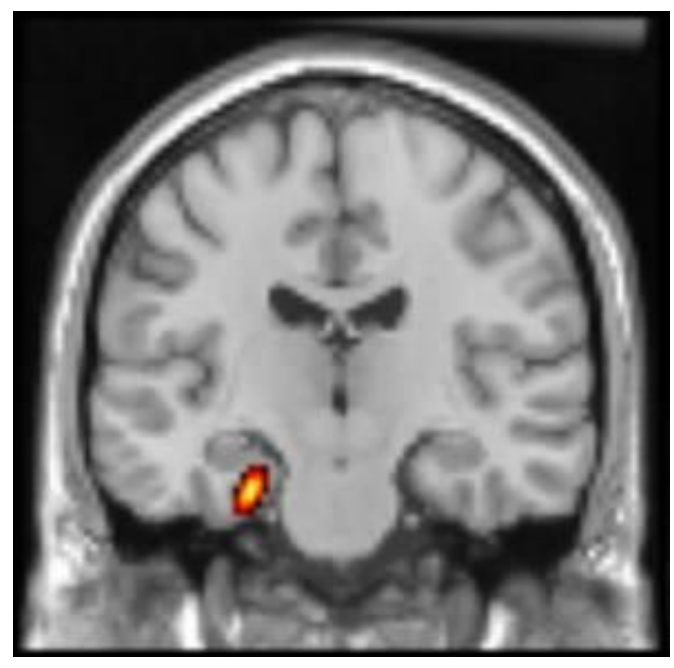




\section{Figure 4 :}

L parahippocampal gyrus [-22 -14 -26]

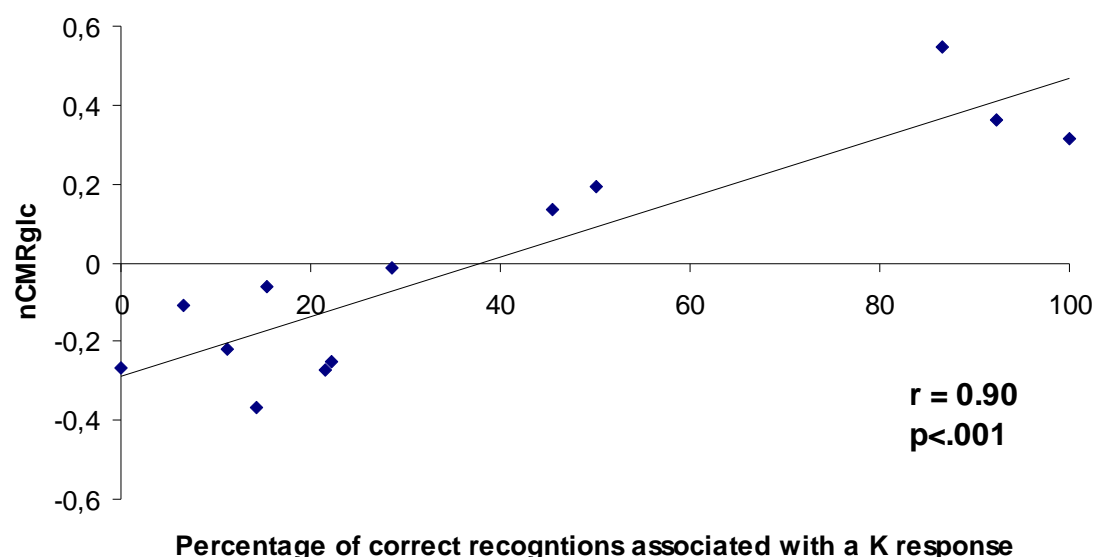

